9 Gendron CE, Poitras LR, Engels ML, et al. Skills training with supporters of the demented. F A $m$ Geriatr Soc 1986;34:875-80. families caring for a relative with a dementing illness. $\mathcal{f}$ Am Geriatr Soc 1985;33:664-9.

11 Katz S, Akpom CA. A measure of primary sociobiological functions. $\operatorname{Int} \mathcal{f}$ Health Serv 1976;6:493-507.

12 Bird KD, Hall W. Statistical power in psychiatric research. Aust $N Z \mathcal{Z}$ Psychiatry 1986;20:189-200.

13 Zarit S, Reever K, Bach-Peterson J. Relatives of the impaired elderly: 2arit S, Reever K, Bach-Peterson J. Relatives of the impared
correlates of feelings of burden. Geromtologist 1980;20:649-54.

14 Fitting $M$, Rabins $P$, Lucas $M J$, Eastham J. Caregivers for dementia patients: a comparison of husbands and wives. Gerontologist 1986;26:248-52

15 Brodaty H, Griffin D, Hadzi-Pavlovic D. A survey of dementia carers: how doctors communicate with dementia patients and their carers; the problem behaviours of dementia; and factors associated with institutionalisation. Aust $N Z \mathcal{F}$ Psychiatry (in press).

16 Blessed G, Tomlinson BE, Roth M. The association between quantitative measures of dementia and of senile change in the cerebral grey matter of elderly subjects. Br f Psychiatry 1968:114:797-811.

17 Folstein MF, Folstein SE, McHugh PR. "Mini-mental state": a practical method for grading the cognitive state of patients for the clinician. Fournal of Psychological Resources 1975;12:189-98.

18 Gilleard CJ, Boyd WD, Watt G. Problems in caring for the elderly mentally infirm at home. Arch Gerontol Geriatr 1982;1:151-8.
10 Kahan J, Kemp B, Staples FR, Brummer-Smith K. Decreasing the burden in

19 Lawton MP, Brodie EM. Assessment of older people: self-maintaining and instrumental activities of daily living. Gerontologist 1969;9:179-86.

0 Hamilton M. A rating scale for depression. I Neurol Neurosurg Psychiatry 1960;23:56-62.

21 Yesavage JA, Brink TL, Rose TL, Adey $M$. The geratric depression rating scale: comparison with other self-report and psychiatric rating scales. In: Crook T, Ferris S, Bartus R, eds. Assessment in geriatric psychopharmacology. New Canaan, Connecticut: $M$ Dowley, 1983.

22 Hughes CP, Berg L, Danzieger WL, Coben LA, Martin RL. A new clinical scale for the staging of dementia. Br f Psychiatry 1982;140:566-72.

23 Goldberg D. The detection of psychiatric illness by questionnaire. New York: Oxford University Press, 1972.

24 Zung WWK. Depression in the normal aged. Psychosomatics 1967;8:287-92. 25 Congalton AA. Status ranking list of occupations in Australia. Appendix B to status and prestige in Australia. Melbourne: FW Cheshire, 1969.

26 Schwartz D, Lellouch J. Explanatory and pragmatic attitudes in therapeutic

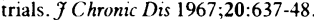

27 Lee E, Desu M. A computer program for comparing $\mathrm{K}$ samples with rightcensored data. Computer Programs in Biomedicine 1972;2:315-21.

28 Wells Y, Jorm AF. Evaluation of a special nursing home unit for dementia sufferers: a randomised controlled comparison with community care. Aust $N$ Zf Psychiatry 1987;21:524-31.

(Accepted 12 September 1989)

The total creatine kinase activity was appreciably

\section{Acute right heart strain after crushing injury at Hillsborough football ground}

\author{
K S Channer, D L Edbrooke, M Moores, \\ P McHugh, S Michael
}

Intensive Care Unit, Royal Hallamshire Hospital, Sheffield S10 2JF

K S Channer, MD, consultant cardiologist

D L Edbrooke, FCANAES, consultant anaesthetist

M Moores, FCANAES, senior registrar in anaesthetics

$\mathrm{P}$ McHugh, FCANAES, senior registrar in anaesthetics

S Michael, FCANAES, lecturer in anaesthetics

Correspondence to: Dr Channer.
Ninety five people died from crushing injuries and asphyxiation at Hillsborough football ground in April 1989. Eighty one others were admitted to hospitals in Sheffield. Of the 18 patients who required artificial ventilation, five were transferred to this hospital for treatment and computed tomography of the head, and one further patient was admitted to this hospital. In all six men (aged 15-23) the brain scan was normal, though they had been asphyxiated by crushing and cerebral hypoxia had occurred. Five had epileptiform convulsions; one had bilateral pneumothoraces and one negative results on laparotomy. None had bone injuries. We report the effect of asphyxiation on cardiac function in these six young men.

\section{Patients and methods}

All six patients were ventilated and examined on admission. Electrocardiograms were recorded daily and echocardiograms on day one and day three or four. Blood samples were taken within the first 24 hours and on days two and three after injury to measure creatine kinase activity, including the myocardial isoenzyme and lactate dehydrogenase isoenzyme 1 activities.

In two patients the initial electrocardiogram showed a nodal rhythm and in one left axis deviation and left bundle branch block. The other four were in sinus rhythm, and by day two all were in and remained in sinus rhythm. The electrical axis was rightward $\left(+90^{\circ}\right)$ in four patients initially, and one patient developed right axis deviation by day two.

There was a dominant $R$ wave in $V 1$ with an $R s R$ pattern in two patients and this appeared by day three in three further patients. T wave inversion developed in leads V1 to V5 in three patients and resolved within two weeks.

Initial echocardiograms showed dilated and impaired right ventricles in four patients. Left ventricular function was reduced in three due to septal hypokinesia. The mean ejection fraction was 0.66 (range $0 \cdot 46-0 \cdot 85$ ), becoming normal in all (mean $0 \cdot 83$, range $0 \cdot 7-0 \cdot 9$ ). Two patients had small transient pericardial effusions, and three had persistent abnormalities of right ventricular function. raised, being compatible with muscle damage, but the cardiac isoenzyme fraction was not raised and the cardiospecific lactate dehydrogenase fraction was slightly raised in all patients (maximum $34 \%$ of total lactate dehydrogenase activity, normal $<25 \%$ ).

\section{Comment}

In all six patients the apparent injury was similarthoracic compression causing hypoxia, loss of consciousness, and convulsions. Unusually, there was no
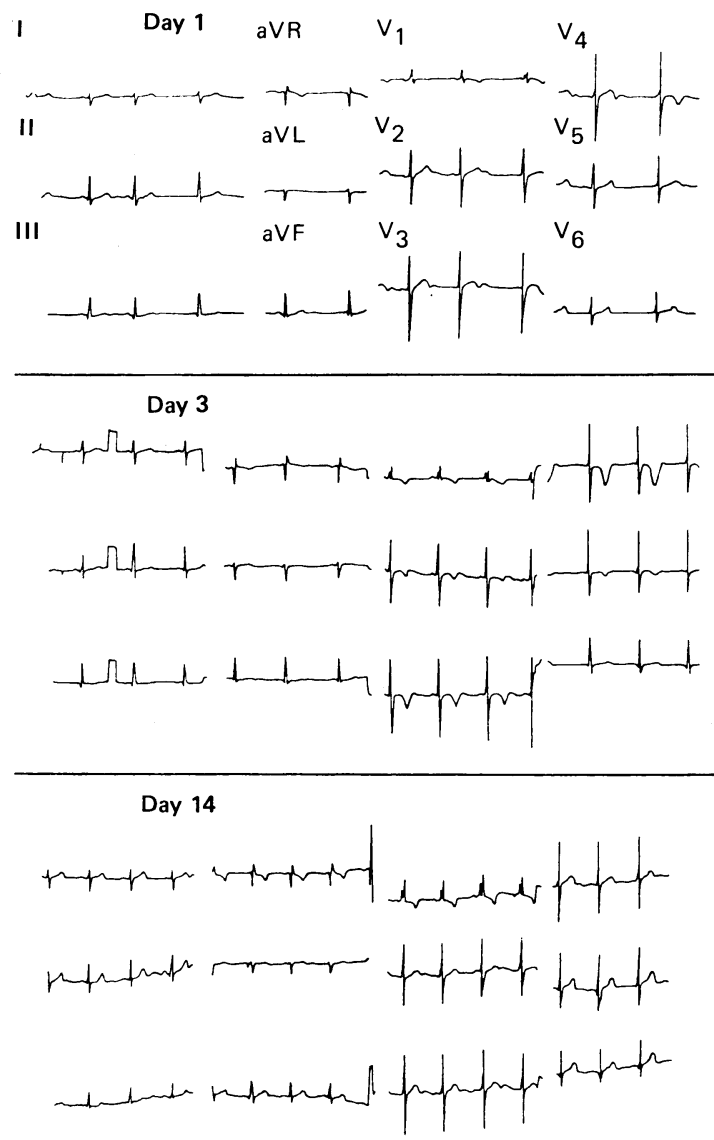

Serial electrocardiographic recordings in one patient. On day one there was right axis deviation, sinus rhythm with blocked atrial premature beats and sinus arrest and nodal escape beats, partial right bundle branch block, and non-specific ST and T wave changes in V3 and V4. On day three axis is $>+90^{\circ}$, and there is complete right bundle branch block. There is marked T wave inversion in VI to V5. On day 14 the axis remains at $+90^{\circ}$, and there is partial right bundle branch block and the $T$ wave changes have resolved 
bone injury. Most cardiac abnormalities after crushing injury occur from blunt trauma after road traffic accidents, where deceleration causes damage to the anterior right ventricle. Electrocardiograms and cardiac enzyme activity are not sensitive indicators of this injury, but radionuclide scanning or echocardiography show abnormalities of right ventricular function..$^{1-3}$ Our patients had acute strain of the right heart because of severe pressure overload which occurs in asphyxiation or with a major pulmonary embolus. One patient only was haemodynamically compromised and required inotropic support.

Acute right heart strain may have occurred for several reasons. External compression, especially of the abdomen, causes increased filling of the right heart . Thoracic compression produces a rise in intrathoracic pressure and pulmonary artery pressure, which would rise further from an increase in pulmonary vascular resistance secondary to hypoxia. The possibility of a pulmonary fat embolus from a crushing injury could not be excluded. ${ }^{4}$ Finally, direct cardiac trauma and contusion of the septum and right ventricle was a possibility, supported by pericardial effusions in two patients and transient conduction abnormalities in two. ${ }^{1.3}$ The electrocardiographic and echocardiographic appearances improved in all six patients, and possibly no long term cardiac damage occurred. We did not test cardiac function, however, and the abnormal right ventricular function may interfere with exercise and normal activity in these young men.

We thank the following anaesthetists for their suppor of these patients: Drs S P Gerrish, P A Wilkinson, T Kirkpatrick, S Gill, A Magides, J McKay, and J Kennedy. We also thank the technical staff of the department of cardiology and the department of medical illustration for their help in preparing this report.

1 Rothstein RJ. Myocardial contusion. FAMA 1983;250:2189-91.

2 Rosenbaum RC, Johnston GS. Post-traumatic cardiac dysfunction: assessment with radionuclide ventriculography. Radiology 1986;160:91-4.

3 Harley DP, Mena I, Narahara KA, Miranda R, Nelson RJ. Traumatic myocardial dysfunction. $\mathcal{F}$ Thorac Cardiovasc Surg 1984;87:386-93.

4 Dehand FH, Bennett WA. Death due to bone marrow and tumor embolisation in the absence of fracture. Archives of Pathology 1957;63:13-6.

(Accepted 23 August 1989)

\section{Fine bore silicone catheters for peripheral intravenous nutrition in adults}

\section{Stanley R Kohlhardt, Ross C Smith}

\section{University of Sydney \\ Department of Surgery, Royal North Shore Hospital, St Leonards, New South Wales, Australia 2065 \\ Stanley R Kohlhardt, MB, research fellow Ross C Smith, MD, senior lecturer in surgery}

Correspondence to: $\mathrm{Dr}$ Kohlhardt. Reprint requests to: Dr Smith.

BrMed f 1989;299: 1380-1
The finest silicone central vein infusion catheter, intended for neonates, has been shortened and adapted for peripheral vein infusion in adults. We hypothesised that this catheter, used with a lipid based nutrition solution suitable for infusion via a peripheral vein, most closely approached the requirements for preventing infusion thrombophlebitis. These include using a short, soft, and flexible fine bore biocompatible catheter; sterile insertion technique; and an infusion solution with an osmolality up to $1000 \mathrm{mmol} / \mathrm{l}$ and $\mathrm{pH}$ greater than $5 \cdot 0 .{ }^{1}$ We therefore studied the complication rate when using this very fine catheter for peripheral intravenous nutrition.

\section{Methods and results}

Consecutive surgical inpatients requiring intravenous nutrition were studied. A fine bore silicone catheter (inside diameter $0.3 \mathrm{~mm}$, outside diameter $0.6 \mathrm{~mm}$, Vygon, Nutricath-S Epicutaneo-cave catheter) was inserted $15 \mathrm{~cm}$ into a median cubital vein. A transparent occlusive dressing secured the catheter, allowing unrestricted arm movement and observation of the puncture site. The catheters were used only for delivering intravenous nutrition.

The nutrition solutions were aseptically prepared in the pharmacy in 3 litre bags with about 100:1 energy (kcal) to nitrogen (g) $(0.42 \mathrm{MJ}: 1 \mathrm{~g}$ nitrogen) and $70 \%$ of non-protein energy supplied as lipid. Vitamins, trace elements, and sodium heparin $(1 \mathrm{unit} / \mathrm{ml})$ were added routinely and ranitidine $(200 \mathrm{mg} / 24 \mathrm{~h})$ when indicated. Mean osmolality was 1084 (SD 6.6) $\mathrm{mmol} / \mathrm{l}$ and $\mathrm{pH} 5.6$ $(0 \cdot 3)$. Patients received more than $35 \mathrm{kcal} / \mathrm{kg} /$ day $(0 \cdot 15$ $\mathrm{MJ} / \mathrm{kg} /$ day) and $0.35 \mathrm{~g}$ nitrogen $/ \mathrm{kg} /$ day using volumetric infusion pumps. Thrombophlebitis (judged by a single observer) was indicated by at least two of the following: erythema, pain, swelling, and tenderness. Phlebitis restricted to the catheter tip indicated chemical phlebitis, and two of the following indicated bacterial phlebitis: fever, heat, increased neutrophil count, and induration with a positive culture from the catheter tip or protracted resolution of inflammation. Bacteraemia was diagnosed by blood culture. Catheter tip culture was performed routinely.

Forty six patients aged 13-89 years received 61 catheters for 704 treatment days. Indications for intravenous nutrition included: gut rest after major surgery (32), pancreatitis (7), active Crohn's disease (3), and other reasons (4). The median duration of infusion was nine days (range 5-60). Thirty four patients required only one catheter, while seven required more than one, and five required a central catheter for some period. Forty one patients were treated with peripheral intravenous nutrition alone until enteral feeding was re-established. The figure shows the probability of continued catheter function. There were 11 episodes of phlebitis ( 10 chemical, one bacterial) with five recorded at completion of treatment. The median period to phlebitis was seven days (range 5-19). Two episodes were due to spontaneous retraction of the catheter with extravasation. Overall the daily risk of phlebitis was $0.016(11 / 704)$ with no instances of bacteraemia or septicaemia related to the catheter. One Staphylococcus epidermidis infection occurred at the insertion site without phlebitis and cleared without antibiotics. Subcutaneous extravasation of infusate occurred six times and fully resolved within 96 hours of the infusion being stopped at that site.

\section{Comment}

Conventional peripheral vein catheters used for nonirritant infusions are associated with an incidence of phlebitis of $30-100 \%$ after five days. ${ }^{2}$ Lipid based

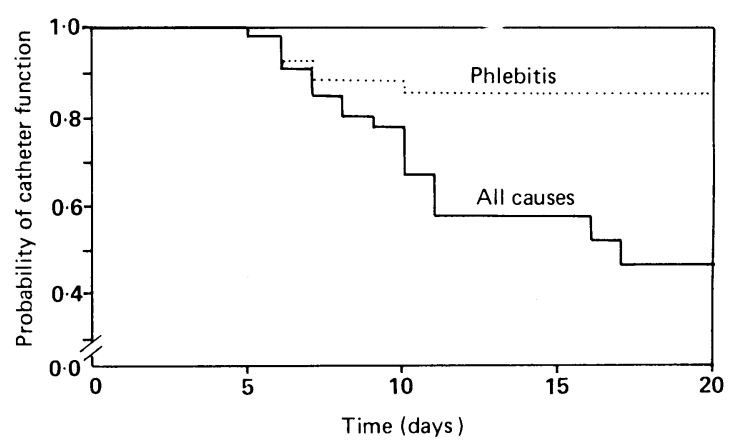

Probability that fine silicone catheters were functioning plotted against time in days as for life table analysis. Dotted line indicates probability of infusion thrombophlebitis 